\title{
A Study to Investigate How Six Thinking Hats Enhance the Learning of Environmental Studies
}

\author{
Saroja Dhanapal (Dr.) ${ }^{1}$, Khoo Tabitha Wern Ling ${ }^{2}$ \\ (Taylors Business School/Taylors University, Malaysia) \\ (Primary Years Programme/Fairview International School, Malaysia)
}

\begin{abstract}
An action research was carried out to create a condition for a class of Year 6 students in their earlymiddle childhood stage to individually and collectively improve their learning by developing higher-order critical thinking skills in the Environmental Studies (ES) subject. In applying the Six Thinking Hats method, with the incorporation of the Revised Bloom's Taxonomy, an active teaching and learning process was seen in the enquiry classroom. Mixed methods of both quantitative and qualitative were conducted in this study to explore and identify the effectiveness of the Six Hats in encouraging higher-order thinking skills and enhancing learners' interests, leading to better academic performances. While results proved the concept to be a successful thinking skill strategy, learners' interests differed in relation to a range of different factors such as values and attitude. Then again, positive responses were seen in pupils' academic progress. Recommendations are thence made regarding these features to maximize learning outcomes and for further research.
\end{abstract}

Keywords: Environmental Studies; Six Thinking Hats and Revised Bloom's Taxonomy

\section{Introduction}

As the widespread interests in developing children's thinking and learning skills is found to be of paramount importance (Fisher, 2005); over the recent years, the Environmental Studies (ES) subject has also grown to be an active area of inquiry. Following the rising concern about environmental quality, it is of no surprise that schools are responding to the matter by increasing environmental-related activity (Hart and Nolan, 1999). Consequently, in order to see a steadfast growth in identifying and finding solutions to environmental issues, it is fundamental that from an early stage of education, children are able to gain these skills through critical thinking and problem solving approaches (UNESCO, 1992). Thus teachers need to be equipped to incorporate thinking skill strategies in the inquiry classroom (King et al., 1998).

In 1985, Dr. Edward de Bono's introduced the Six Thinking Hats (a thinking skills tool) which allow thinkers to simplify thinking by dealing with points consecutively and carry out 'a switch in thinking' (De Bono, 1999). Whereas the Six Thinking Hats is prominent for carrying out parallel thinking, the Environmental Studies subject "emphasizes specific critical thinking skills central to "good science" - questioning, investigating, forming hypotheses, interpreting data, analyzing, developing conclusions, and solving problems' (NEEF, 2010:2). A key to connecting and enhancing the two features is through the incorporation of the Taxonomy of Educational Objectives which may support the evaluation of the Six Hats in the Environmental Studies as it 'is a scheme for classifying education goals, objectives, and most recently, standards' (Krathwohl, 2002:218).

For the reason that the Six Thinking Hats, ES subject and Bloom's Taxonomy are seen to enhance different thinking skills, this study aims to explore how the Six Hats may act as a catalyst in challenging students to obtain higher level thinking processes and increase learners' interests in learning Environmental Studies. Additionally, the application of the Bloom's Taxonomy will be examined to enhance the effectiveness of the Six Thinking Hats. Thus, the two questions central to this study in investigating how the Six Thinking Hats may enhance the learning of Environmental Studies are:

1) Does the Six Thinking Hats method encourage higher-order thinking skills?

2) Does the Six Thinking Hats increase students' interest in learning Environmental Studies?

\section{Review of Literature}

The requisite of teaching thinking skills is perceived by the growing awareness of the change in society and skills that may no longer be appropriate to prepare students for the world beyond school (Fisher, 1999). Fisher asserts that 'the basic premise of a 'thinking skills' approach to education is that the quality of our lives and of our learning depends in large part on the quality of our thinking' (1999:52). Thus, today's curriculum thrives towards teaching students how to think (Schafersman, 1991). In order to assist instructors, three ingredients to teaching critical and even creative thinking have been identified by Helgeson: 'using relevant, real world issues; providing structure to solve problems and organize information, and a nurturing classroom environment.' (1993 cited in Marrapodi, 2003:20). The ES subject complies with this as it requires a problem 
solving, inquiry based approach (UNESCO, 1994) to analyze 'a wide range of environmental problems, issues and information' (Chiras, 2010:10).

As we are aware, education consists of two main goals which are transmitted to students: the first goal, "what to think", is the transmitting of subject matter and acquiring basic knowledge; the second, "how to think" or critical thinking, involves cognitive process instruction (Schafersman, 1991). In the process of understanding 'critical thinking', many definitions and descriptions have been given to the term (Schafersman, 1991; Marrapodi, 2003; Carmichael, 2006). While some theories use the term interchangeably with 'higher-order thinking skills (HOTs)' (Schafersman, 1991), others believe that critical thinking is included in higher order thinking skills along with creativity and other thinking skills (King et al, 1998; Marropodi, 2003). Nonetheless, common elements have been distinguished such as information processing, analysing, problem solving, and metacognition (Fisher, 1999). Often as the second goal, "how to think", is so subtle, instructors and students fail to recognize and realize its absence (Schafersman, 1991). Thankfully, Bloom's Taxonomy (1950) clears this vagueness as it acts as a base to critical thinking by providing 'a framework for classifying statements of what we expect or intend students to learn as a result of instruction' (Krathwohl, 2002:212). As shown in Fig. 1, thinking skills in both the original taxonomy and the revised Taxonomy by Anderson (1990) are organised 'into six levels, from the most basic to the higher order levels of thinking' (cited in Tarlinton, 2003:6). While the original taxonomy develops in the cognitive domain, the revised taxonomy consists of a two-dimensional framework: knowledge and cognitive processes (Krathwohl, 2002). As such, Anderson explains that the shift of the six categories from noun to verb forms is to reflect the different forms of thinking as an active process (1990 cited in Tarlinton 2003:8).

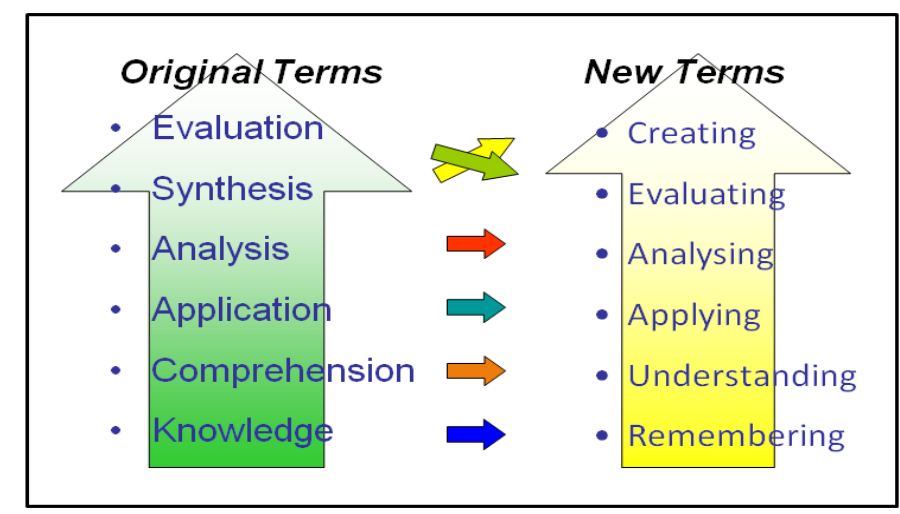

Figure 1: Revised Bloom's Taxonomy (Based on Pohl, 2000 cited in Tarlinton, 2003:7)

Similar to the transmit of 'what to think' and 'how to think', Bloom's taxonomy is divided into lower order and higher order thinking skills; where the lower order levels acts as a base for the higher order thinking skills which are focused on the top three level's of the Taxonomy: analysis, evaluation and creativity (Marrapodi, 2003; King et al., 1998). Higher order thinking skills is thus grounded in the lower order skills 'such as discriminations, simple application and analysis, and cognitive strategies and are linked to prior knowledge of subject matter content' (King et al, 1998:35). By successfully applying these skills, King et al explains that it will 'result in explanations, decisions, performances, and products that are valid within the context of available knowledge and experience, and promote continued growth in these, as well as other intellectual skills' (1998:32).

While Bloom's Taxonomy has been the mainstay in higher level thinking skills (McAleer, 2006), often referenced to connect critical thinking and creative thinking (Marrapodi, 2003), the "Six Thinking Hats" is a thinking tool which De Bono's describes as 'a simple, effective parallel thinking process that helps people be more productive, focused, and mindfully involved' (2011). In applying the Six Hats, students are stimulated to think and control their own learning (Kruse, 2010) as it requests specified modes of thoughts which allows the thinker to simplify thinking by dealing with points consecutively and allows 'a switch in thinking' as mentioned (De Bono, 1999). Hart and Nolan emphasize that the purpose of employing thinking tools in the inquiry classroom is 'for teachers and students to work with and as inquirers to confront their own notions and ideas about the way the world works and about the meaning of teaching and learning as a process rather than mere knowledge acquisition' (1999:41).

Fig. 2 provides an explanation of the Six Thinking Hat's usage. In contrast to Bloom's taxonomy, the Six Hats has no fixed order (House et al., 2011). However, when applying this parallel thinking skills concept, thinkers are required to look in the same direction at any one point, though the direction can be changed (De Bono, 1999). As ideas are encouraged to be explored from a variety of angles, it provides a space for critical thinking and creativity (House et al., 2011; Marrapodi, 2003). 


\begin{tabular}{|l|l|}
\hline $\begin{array}{l}\text { White Hat Thinking: } \\
\text { Just the facts }\end{array}$ & $\begin{array}{l}\text { The white hat calls for information known or needed. When you ask for } \\
\text { white hat thinking you are asking what information is needed, what is } \\
\text { available and how it can be obtained. }\end{array}$ \\
\hline $\begin{array}{l}\text { Yellow Hat Thinking: } \\
\text { Benefits. Pluses. }\end{array}$ & $\begin{array}{l}\text { The yellow hat explores the positives and probes for value and benefit. } \\
\text { The yellow hat role is for discussing ONLY the positive view of problems } \\
\text { and possibilities for solutions. }\end{array}$ \\
\hline $\begin{array}{l}\text { Black Hat Thinking: } \\
\text { Difficulties. Problems. }\end{array}$ & $\begin{array}{l}\text { The black hat is logical and critical judgment: why something may not } \\
\text { work. Spot the difficulties and dangers. The black hat points out what } \\
\text { cannot be done. The hope is that the black hat will prevent us from } \\
\text { making mistakes. }\end{array}$ \\
\hline $\begin{array}{l}\text { Red Hat Thinking: } \\
\text { Intuition. }\end{array}$ & $\begin{array}{l}\text { The red hat signifies feelings, hunches and intuition. When using this hat } \\
\text { people can express em otions and feelings and share fears, likes, dislikes, } \\
\text { loves and hats. They don't' need to justify their statements. }\end{array}$ \\
\hline $\begin{array}{l}\text { Green Hat Thinking: } \\
\text { Creativity. Ideas. }\end{array}$ & $\begin{array}{l}\text { The green hat is an opportunity to express new concepts and new } \\
\text { perceptions. People can generate alternative solutions or courses of } \\
\text { action, put forward possible explanations or hypotheses, create new } \\
\text { scenarios or future states, or generate possible designs. }\end{array}$ \\
\hline $\begin{array}{l}\text { Blue Hat Thinking: } \\
\text { Managing the thinking. }\end{array}$ & $\begin{array}{l}\text { The blue hat deals with controlling the thinking process. The blue hat is } \\
\text { sometimes 'given' to one person, who controls which hat will be 'worn', } \\
\text { hence controlling the type of thinking being used. The blue hat comments } \\
\text { on the thinking being used, asks for conclusions, decisions, etc. }\end{array}$ \\
\hline
\end{tabular}

Figure 2: Six Thinking Hats (Kruse, 2010:71)

Fisher states that effective learning 'involves not only thinking, but a metacognitive process: thinking about thinking' (1998 cited in Fisher 1999:54). This coincidently aligns with the Blue Hat which controls the thinking process (Kruse, 2010) and 'evaluation' which makes 'decisions based on in-depth reflection, criticism and assessment' (Tarlinton, 2003:28). As seen, true critical thinking is higher-order thinking as it means 'correct thinking in the pursuit of relevant and reliable knowledge about the world' - thinking about thinking (Schafersman, 1991).

Although testimonials from schools such as the Franny McAleer's Group and leading companies have found the Six Thinking Hats to be effective (De Bono, 2011), few literatures are found to help situate the research of how the STH may enhance the learning in ES. One case study analysis was conducted by Ballantyne et al. (2001), which compared the "Six Thinking Hats" with another thinking skills strategy, "Story Walk". Even though results from the research revealed a variation in students' interests, knowledge, attitudes and actions, both strategies were found to be 'successful in raising students' awareness of environmental issues' (Ballantyneet et al., 2001:11)

\section{Methodology}

An action research consisting of mixed methods was carried out with the purpose of studying a real school situation 'to improve the quality of actions and results within it' (Schmuck, 1997 cited in Mertler, 2006), increase student learning as well as to understand learners' perspectives (Mertler, 2006). While data analysis is based largely from the responses given by students and to a small degree, from teachers, in the survey questionnaires, other forms of research methods were used to maximize the richness and accuracy of the study. The forms of quantitative methods used in the research include the numerical results achieved from students' end-term examination and class projects/presentations whereas the qualitative research methods consist of feedbacks from participant observation and weekly summary entries of self-reflections. The essence of employing a qualitative research is that it allows more flexibility to the exponent to identify intangible factors through a complex textual description which is important to help 'interpret and better understand the complex reality of a given situation and the implications of quantitative data' (Mack et al., 2005: 2).

In carrying out the surveys, it was brought to the attention of the researchers in the initial stage that there were some inconsistencies in the findings. As a result, a subsequent survey questionnaire was designed to verify the validity of the previous results. The survey was more reflective in nature as it required participants to reflect on their learning progress and efforts put in the end-of-the term examination. While few questions were similar to the first survey, Part B of the survey encouraged learners to reflect on their achievement and to ponder upon future progression. In the second survey, an additional question was added to Part A with the intention to identify learners' own reflection of their thinking skills in relation to Bloom's Taxonomy. 
The proposed research was carried out for a term, with a sample of 20 Year 6 international students in the age range between 10-12 years. Due to the frequent absenteeism, however, the affirmed participants consisted of merely 18 learners. Out of which, 16 were classmates in the previous term; while two arrived this term and were therefore new to the subject. Regardless of the fluctuation in attendance, the two main environmental topics covered over the eight teaching weeks were: "Seasons" and "Satellites". Additionally, the two weeks of revision covered Term 1's syllabus as well. Topics included "Weather in general", "Hurricanes and Storms", "Clouds, Water and Ice", "Tides and Oceans" and "Atmosphere". Inevitably, the technique of applying the Six Thinking Hat strategy was accentuated in the first few ES lessons to ensure effective learning and successful implementation. With the intention of guiding students to focus their thoughts to achieve higherorder and critical thinking skills, the theoretical framework designed for this study as shown in Fig. 3 connects the Six Thinking Hats Theory with the revised Bloom's taxonomy, for the primary level's use.

\begin{tabular}{|c|c|c|}
\hline & Six Thinking Hats & Thinking Skills Applied \\
\hline Creating & $\begin{array}{l}\text { GREEN HAT } \\
\text { Creativity }\end{array}$ & $\begin{array}{l}\text { Generating new ideas, products or } \\
\text { ways of viewing things } \\
\text { What new idess are possible? } \\
\text { What is my suggestion? } \\
\text { Can I create something new? }\end{array}$ \\
\hline Evaluating & $\begin{array}{c}\text { BLUE HAT } \\
\text { Thinking about Thinking }\end{array}$ & $\begin{array}{l}\text { Justifying a decision or course of action } \\
\text { What thinking is needed? } \\
\text { Where are we now? } \\
\text { What is the nextstep? }\end{array}$ \\
\hline Analyzing & $\begin{array}{c}\text { BLACK HAT } \\
\text { Judgement }\end{array}$ & $\begin{array}{l}\text { Breaking information into parts } \\
\text { to explore understandings and relationships } \\
\text { What is wrong with this? } \\
\text { Will this work? Is it safe? } \\
\text { Can it be done? }\end{array}$ \\
\hline Applying & $\begin{array}{c}\text { YELLOW HAT } \\
\text { Benefits }\end{array}$ & $\begin{array}{l}\text { Using information in another familiar situation } \\
\text { What are the good points? } \\
\text { Why can this be done? } \\
\text { Why is this a good thing? }\end{array}$ \\
\hline Understanding & $\begin{array}{l}\text { RED HAT } \\
\text { Feelings }\end{array}$ & $\begin{array}{l}\text { Explaining ideas or concepts } \\
\text { How do I feel about this? } \\
\text { What do I like about the idea? } \\
\text { What don't I like about this? }\end{array}$ \\
\hline Remembering & $\begin{array}{l}\text { WHITE HAT } \\
\text { Information }\end{array}$ & $\begin{array}{l}\text { Recalling information } \\
\text { What information do I have? } \\
\text { What are the facts? } \\
\text { What information do I need? } \\
\text { What do I want to KNOW? }\end{array}$ \\
\hline
\end{tabular}

Figure 3: Theoretical Framework of this study.

In order to identify students' interests, a survey was carried out with all 16 students present in the class. To ensure the quality of the data, besides identifying learners' perception, views of experienced teachers were also taken into account. In addition, a colleague was invited to conduct semi-structured observations in four different classes, spread relatively evenly over the term. The purpose of this was to carefully observe the progress in the learning environment and records were kept using observation forms. Other than observing the teaching periods, the participant was asked to observe students' group presentations on two different occasions. The first topic 'Seasons' was presented in the $4^{\text {th }}$ week and the second topic 'Satellites' was presented in the $8^{\text {th }}$ week as a close to each of the term's main topics. After each group presentation, students were given comments based on knowledge and understanding; skills and organization; presentation and effort shown. The results were graded according to a preset marking criteria. Finally, as examination keeps a record of students' academic progress, students' academic achievements were assessed through the end-of-the term examination results which were compared to the previous term's results.

\section{Findings and Discussion}

According to the research objectives, the researchers employed a triangulation method to analyse the data obtained through the various methods discussed to investigate how the Six Thinking Hats may enhance students' higher-order thinking skills and increase learners' interests in learning Environment Studies.

\section{Development of Higher-Order Thinking Skills through the Six Thinking Hats}

According to UNESCO, the main aim of Environmental Education is:

to aid learners in becoming environmentally knowledgeable and, above all, skilled and dedicated human beings, who are willing to work, individually and collectively, toward achieving and/or maintaining a dynamic equilibrium between the quality of life and quality of the environment. 
(1994)

In order to achieve this aim, students must engage in 'deep learning', where the understanding is integrated with new information (Davis, 2009). Thus, the Six Thinking Hats (STH) concept was introduced to the Year 6 Environmental Studies (ES) classroom to encourage such learning. Since that 'what and how much is learned in any situation depends on a student's prior knowledge and experience' (Davis, 2009:262), students' prior knowledge and application of the STH were identified through the pre-survey questionnaire. As shown in Fig. 4, a high percentage of 77.8 students have heard of the STH as this thinking skills strategy is strongly encouraged in the school setting. Then again, despite the basic knowledge that such a tool exist, only an average of $54.2 \%$ students have applied the STH method before.

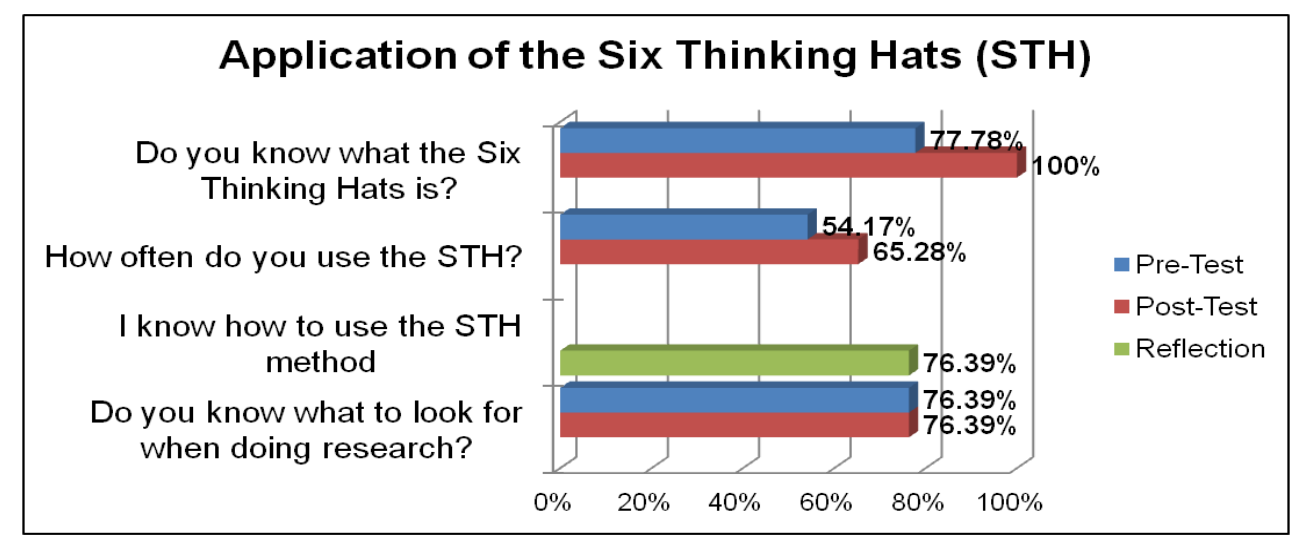

Figure 4: Applying the Six Thinking Hats

It was anticipated that through the successful implementation of the Six Hats in the term, pupils would be encouraged to use the thinking skills tool more frequently and effectively. Although results from the postsurvey aligns with the above statement as an increase from $54.2 \%$ to $65.3 \%$ is seen in students' frequency of applying the STH, the equal percentages of $76.4 \%$ in students' knowledge before and after using it for research, questions the effectiveness of the Six Hats. As shown in Fig. 4, students' confidence level in knowing what to look for when doing research has not altered after learning to apply the STH. This contributes to the idea that little or no difference is made with or without the Six Hats. Then again, as pupils' reflection of their knowledge in applying the STH is above average, it can be concluded that with more time, learners' application of STH for research will be more effective.

Despite this, the STH concept was proven successful in increasing students' academic performances. As seen in the comparison of pupil's Term 1 and Term 2 examination results, besides a small drop of less than $5 \%$ in student L's grades, the rest of the students showed some progress with some exhibiting a great jump of improvement (see Fig. 5). The results of student B and student E (who were new students in the second term) were not included in the calculation as the researchers did not have their Term 1 results to do the comparison. While student $\mathrm{F}$ showed no progress from the examination in term 1 and student $\mathrm{G}$ showed less than $5 \%$ in improvement, the rest of the class had more than $5 \%$ increase in grades, with student $\mathrm{K}$ showing the most progress of approximately $40 \%$.

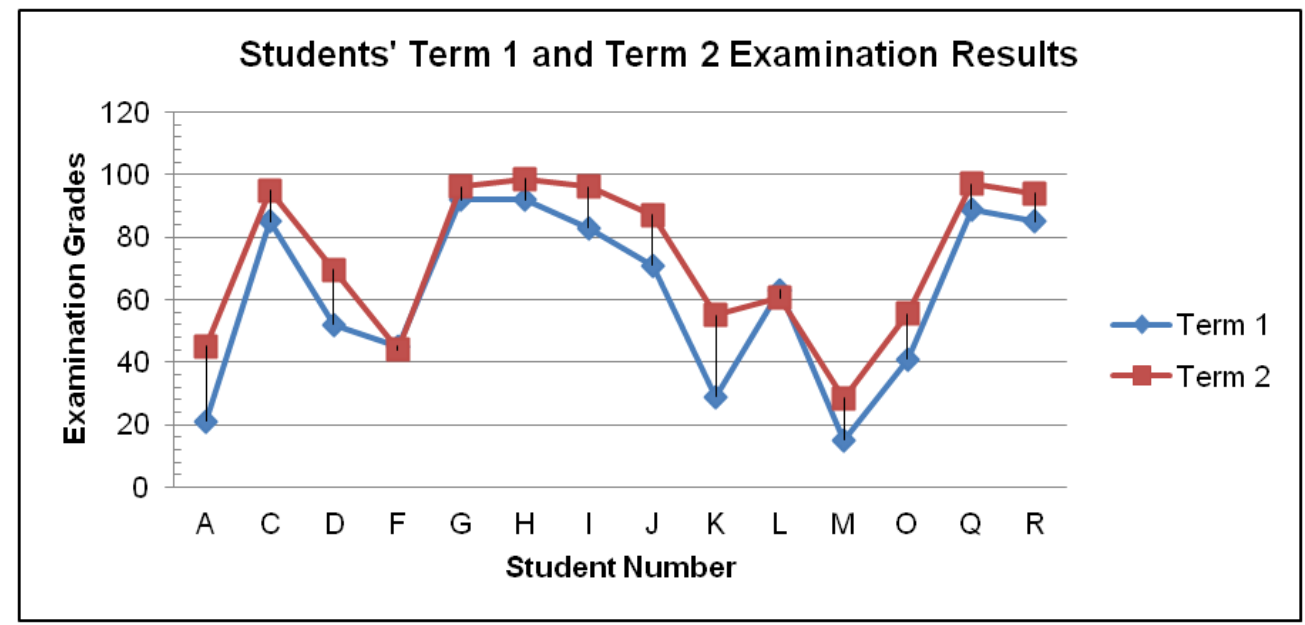

Figure 5: Comparisons of Students' Term 1 and Term 2 Examination Results 
Additionally, data analysis on the application of STH affecting the development of higher-order thinking skills were obtained through the two group presentations as stated in the methodology chapter, based on the two topics: seasons and satellites. In studying the different group results, a minimum of $10 \%$ increase in the second task is found in comparison to task 1 (see Fig. 6). Group 2 did even better, scoring approximately $30 \%$ more in the $2^{\text {nd }}$ task, proving that the application of STH does support their learning and presentation.

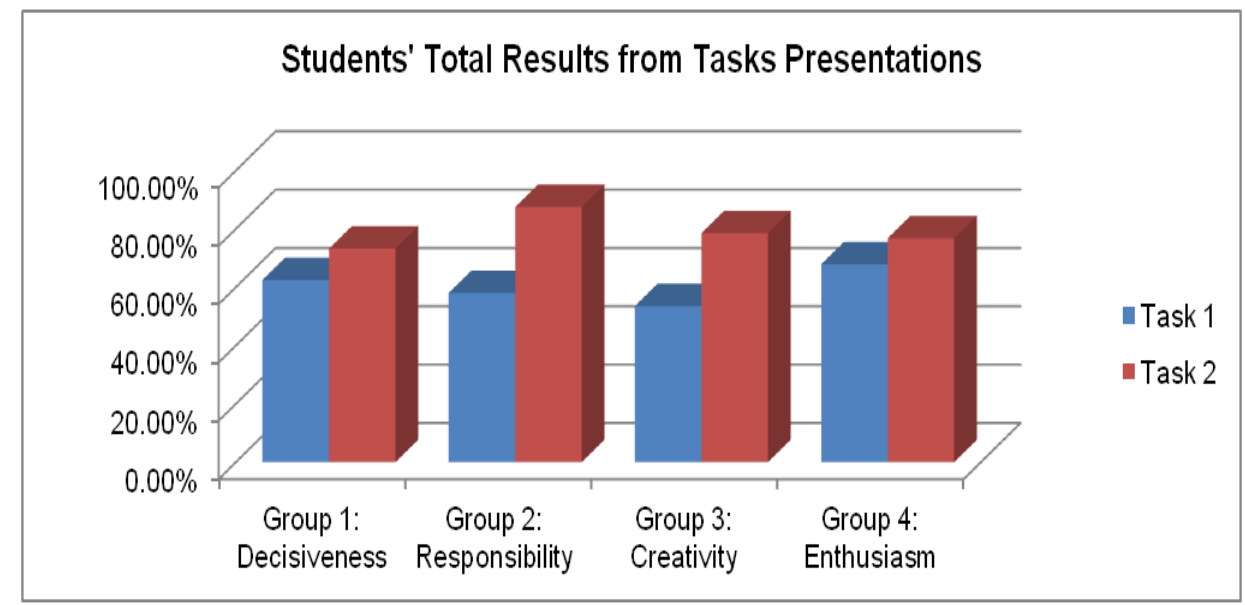

Figure 6: Students' Total Results from Tasks Presentations

Moreover, when the results were analysed in detail as shown in Fig. 7, according to (a) knowledge and understanding; (b) skills which include research, reading and drawing; and (c) organization and presentation, the average percentage that the whole class achieved showed much improvement in the second task compared to the first. This is more so in the development of knowledge and understanding, as well as in skills which had a $20 \%$ and $25 \%$ increase correspondingly. As the development of higher-order thinking skills include analyzing and evaluating for research, the high increase in the development of skills is significant.

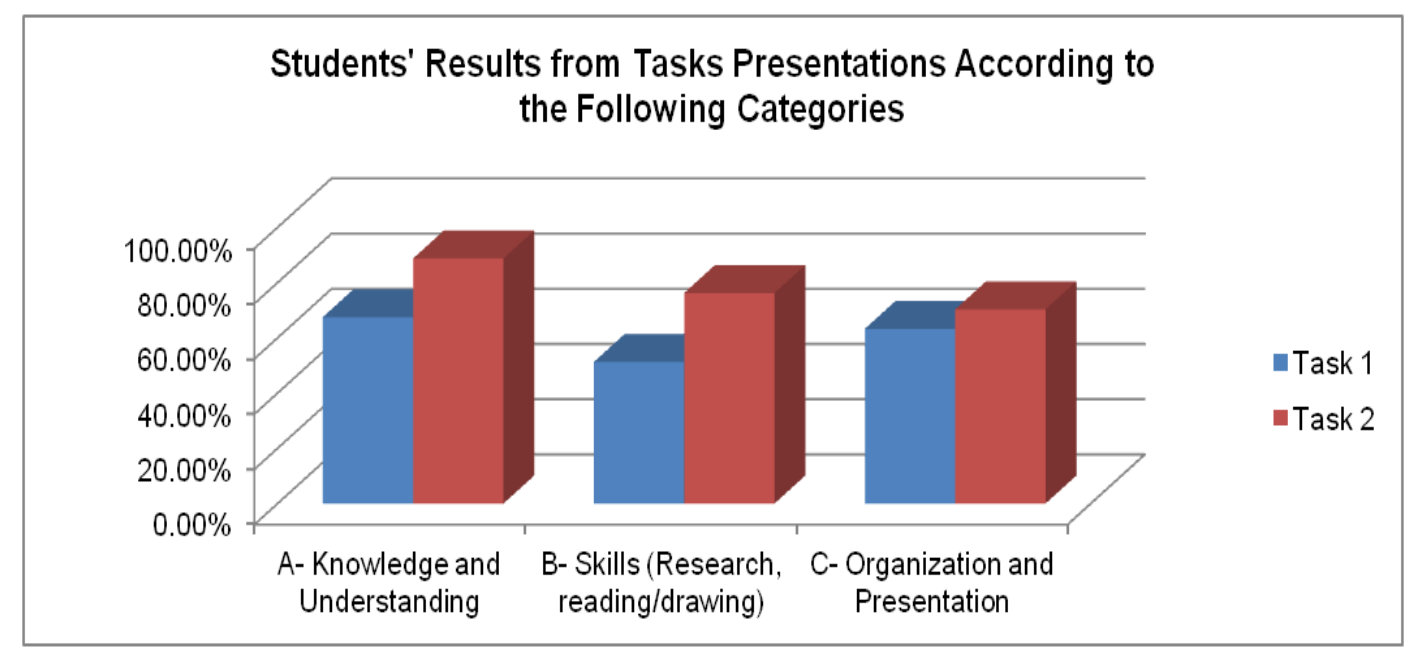

Figure 7: Students' Results from Tasks Presentations according to Sections

The results from the students' presentations (refer to Fig. 6 and 7) assert to the positive result that the application of the Six Thinking Hats does support the development of higher-order thinking skills in Environmental Studies. In reference to this study's theoretical framework, as students' learn to apply all Six Hats, they would develop higher-order thinking skills. As shown in Fig. 8, the results indicate an increase of approximately $5 \%$ which proved that the students are able to remember and find differences after using the STH. Consequently, as students apply parallel thinking to their learning and discussion, learners find themselves able to understand their environment better. 


\section{Students' Perception on the Impact of Studying Environmental Studies}

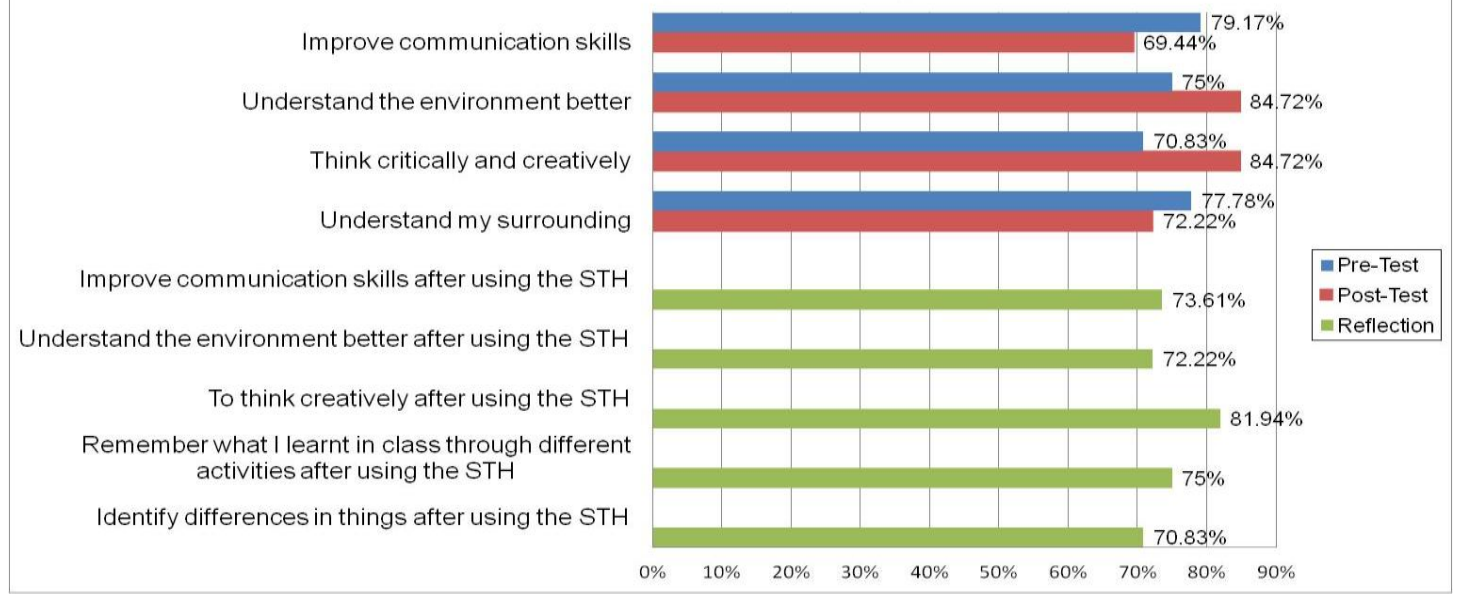

Figure 8: Students' Perceptions on the Impact of Studying Environmental Studies

Although a drop of about $10 \%$ is shown in students' view of how Environmental Studies have helped them in their communication skills, a high percentage of $73.61 \%$ is shown in students' perceptions of how much the STH has helped them improve in their communication skills. Additionally, despite the fact that results show a decrease of 5\% in 'understanding my surrounding', students showed a much greater increase in their understanding of the environment. This is seen in the presentation of tasks (Fig. 6) as students' organization and presentation skills have improved as they learned to present their thoughts more effectively.

In the process of applying the STH, students were also found to have developed in their higher-order thinking skills as critical thinking and creative thinking are encouraged in the lessons. Results of students' reflection proved a great percentage of $81.94 \%$ in 'how much STH has supported their creative thinking'. Additionally, this is found to be linked to the subject as results from the post test proved a greater percentage of more than 14\% in how much Environmental Studies has helped improve students' critical and creative thinking skills. The finding thus implies that while the Six Hats have supported pupils' creative thinking, the enhancement of students' creativity is linked to the subject area as well.

\section{Development of Students' Interests in Learning Environmental Studies}

In reflecting upon the teaching and learning process over the term, focus was primarily place on questions and answers. However, as time passed, the Six Hats was seen constructive to not just the learners, but for teachers' instruction. Drawing closer to the middle of the term, the facilitator began to initiate the STH in lesson planning. Unexpectedly, the STH was found to be more useful in planning out lessons than it was applicable in carrying out activities for every lesson. While the white hat was most appropriate for all lessons, the blue and green hats were seldom used in class activities. The reason for this, however, is partly due to the topic delivered in the class. For instance, the enquirers found it very challenging to come up with new ways in which people can enjoy or protect themselves from a particular season. While the green hat for creating was not very applicable for the topic 'seasons', explorers were able to use their creativity skills to design a satellite of their own. Besides identifying the application of the STH, students' views about the ES classes/ subject were also considered in relation to students' interests in the research

Through the implementation of the Six Thinking Hats in the ES classes, an increase of students' interests in the ES subject is deemed likely. Results from Fig. 9, however, showed a decrease in students' liking to the subject and enjoyment in class was found. In comparing the pre and post test results of students' liking for the ES subject, a drop of $2.78 \%$ was seen. Yet, students' reflection of liking the ES subject in comparison to the post test, showed an increase of $1.39 \%$. Nonetheless, the result of students' reflection is still $1.39 \%$ lower than the pre-test. The decrease in interest of the subject is consequently deemed to be related to the implementation of Six Thinking Hats in the classroom as a decrease of more than $4 \%$ is seen in students' liking of the ES classes and activities conducted. The result of this may be due to the number of activities conducted in the ES class because students felt that there were less activities conducted in class during the later part of the term. In comparing the results of 'the number of activities conducted in ES classes', a drop of $2.78 \%$ is found in students' response in the post test results in comparison to the pre test results. On the other hand, when students reflected on the activities conducted over the term, a higher percentage of $76.39 \%$ is seen. All the same students' reflection of the overall ES activities during the term was positive as a high percentage of $77.78 \%$ is noted, just as students showed satisfaction for their examination results. 


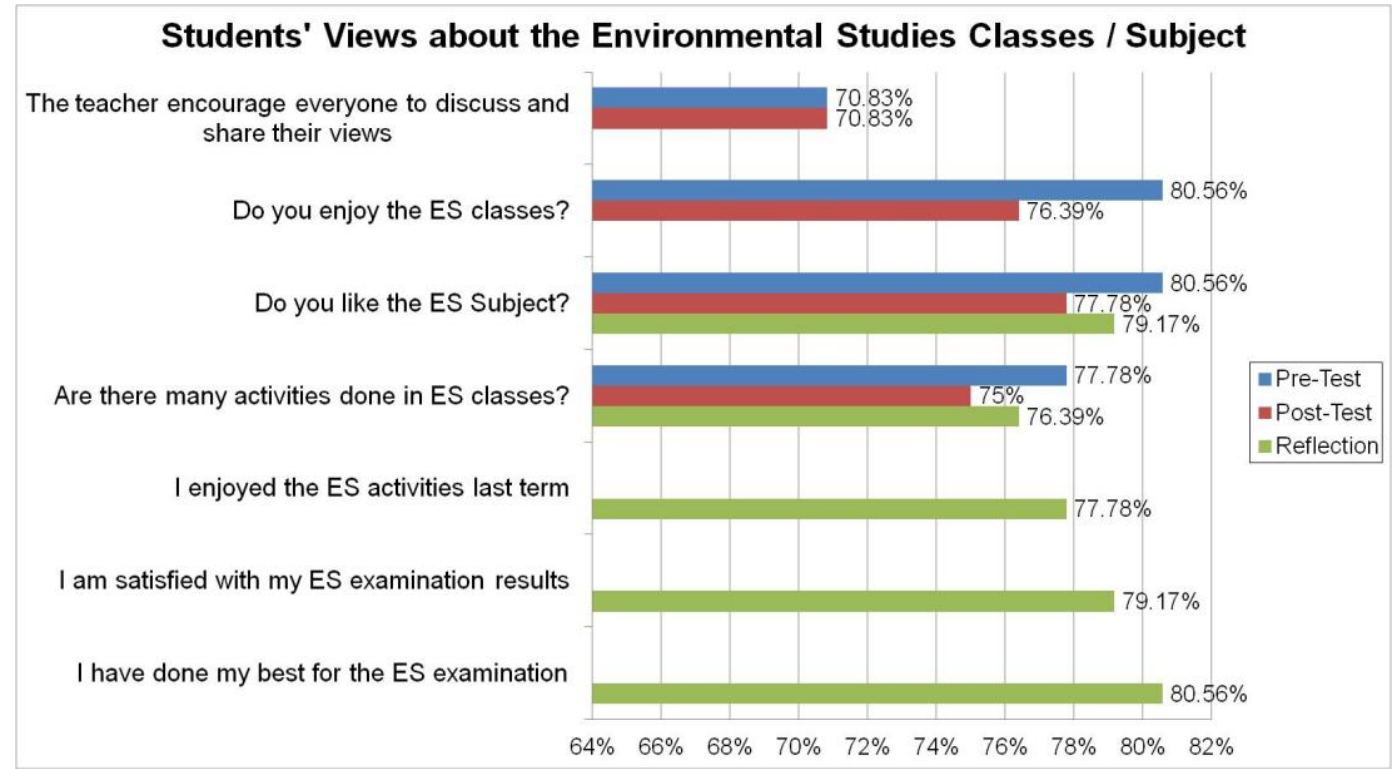

Figure 9: Students' Views about the Environmental Studies Classes / Subject

Students' view of the teacher is seen to not influence students' view of the ES subject as the percentage of students' perception on 'teachers' encouragement to students in class' did not vary with time. Therefore, students' perception of the Environmental Studies classes is found to be very much dependable on their preference in the overall activities conducted over a period of time in class. All the same, to identify whether learners' interests had increase in the course through the usage of the STH, a link has been made between students learning of ES and use of the STH. As shown in Fig. 10, learners' interests appear to vary according to different practices.

Only a small percentage of less than $1 \%$ is seen in learners' interests gained in researching because of the ES subject. Nonetheless, the percentage is high as it is above $80 \%$. In comparing the study of ES with and without the STH, students showed preference and gained more interest in researching without the STH. This is evident as results of students' interests gained in researching and even learning with the STH is more than $2 \%$ less than the response given to studying ES without the STH. The low results of students' preference of using the STH is seen to be related to their conception of an inquiry classroom as students' response towards sharing knowledge and understanding as well as in researching on the topics learnt demonstrated a decrease of more than $4 \%$ for each. Interestingly, students completed more reflections after lessons as there is an increase $2.78 \%$.

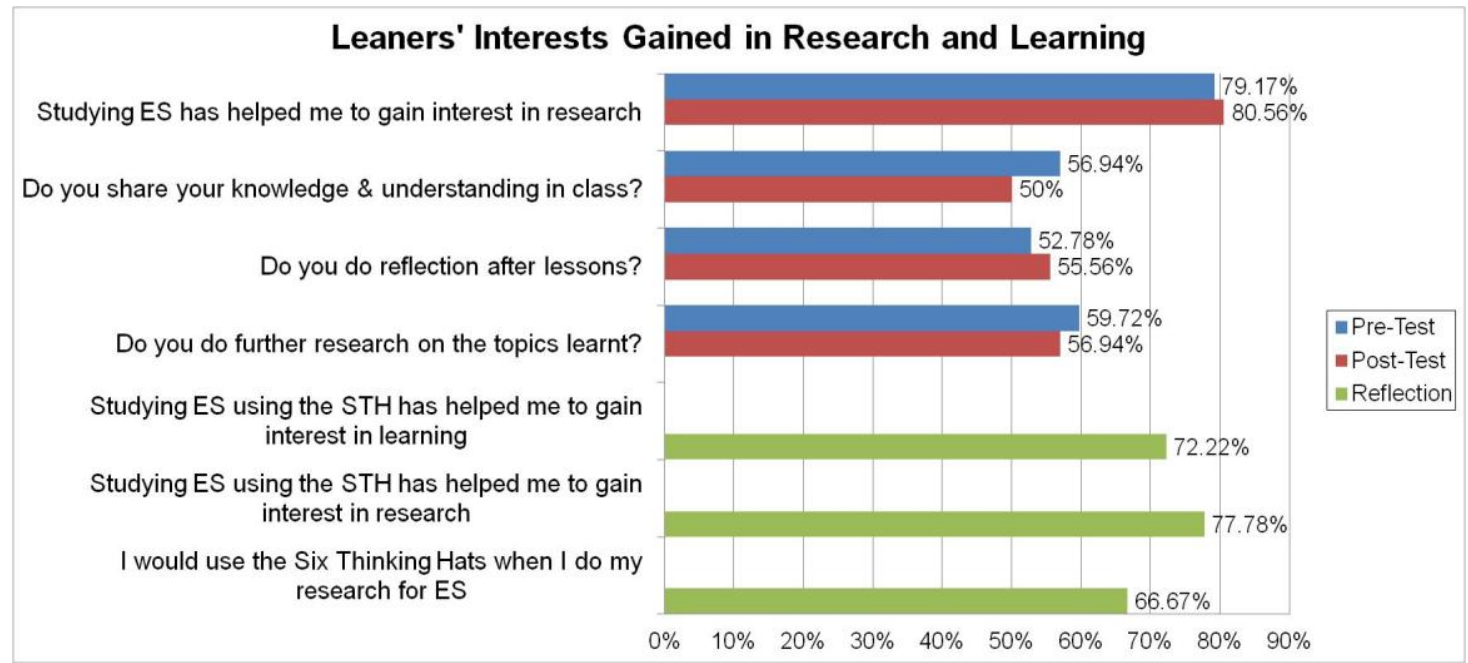

Figure 10: Learners' Interests Gained in Research and Learning

Despite students' dislike towards the STH, it is evident that the application of the thinking skills tool is nevertheless able to enhance students' thinking skills. It is thus not surprising that students' usage of the STH have increased over the term (Fig. 4) as $66.67 \%$ of the students' state that they would use the STH when doing their own research (Fig. 10). Then again, though several results show positive increase in learners' interests, in 
comparison, students' response to "studying ES using the STH has helped me to gain interests in research" in comparison with not using the Six Hats, seems less favourable. Whereas few results show high percentage of learners' interests in research and learning, the negative responses found in students' frequency to do 'further research on the topics learnt' in class and 'willingness to share knowledge and understanding' show less enthusiasm in their learning. Then again, a good response is seen as learners learn to perform more selfreflection.

The above results are also evident in some of the students' responses tabulated in table 4.1. As shown in student $\mathrm{E}$ and student J's responds, regardless of their perspectives of the Environmental Studies classes, the Six Thinking Hats were useful in carrying out activities as it helped in organizing the thinking process and in asking the right questions. Conversely, even though student L 'did not mind' the ES classes, he/she did not find the Six Thinking Hats helpful. Nonetheless, as mentioned by student L (see Table 4.1), a reason to why the STH is not utilized well is because the child is not fully aware of its importance. Consequently, in evaluating this aspect, it is recognized that building the awareness of applying the Six Hats and a call for positive attitudes towards applying it is vital. In the learning process, the challenges and barriers faced by students should hence be taken into consideration.

Table 1: Responses from Students

\begin{tabular}{|l|c|l|}
\hline Question & Student & Respond \\
\hline $\begin{array}{l}\text { Did you enjoy the } \\
\text { Environmental Studies } \\
\text { classes last term? } \\
\text { Explain why. }\end{array}$ & $\mathrm{E}$ & Yes, because of the activities. \\
\cline { 2 - 3 } $\begin{array}{l}\text { Eid the Six Thinking Hats } \\
\text { help you to think better } \\
\text { when doing activities? If }\end{array}$ & $\mathrm{J}$ & $\begin{array}{l}\text { Not really, we sometimes couldn't understand what did the } \\
\text { teacher said, because she talked too fast. }\end{array}$ \\
\cline { 2 - 3 } $\begin{array}{l}\text { yes, explain was it } \\
\text { useful. If no, explain why } \\
\text { it is not useful. }\end{array}$ & $\mathrm{J}$ & I don't mind. Sometime it's fun and boring. \\
\cline { 2 - 3 } & $\mathrm{L}$ & No. It wasn't useful because I didn't care the Six Hats. \\
\hline
\end{tabular}

\section{Conclusions and Recommendations}

In summary, the Six Thinking Hats is found to enhance the learning of ES as parallel thinking enhances students' development to find a connection and understanding of what they learn. Consequently, the STH has also proven to be a successful thinking tool to develop children's higher-order thinking skills as critical and creative skills are developed through the learning. Although there are yet many factors influencing the effect of students' interests in learning, thinking skills strategies are encouraged to be introduced and employed in the enquiry classroom at an early stage of education. By equipping learners with the necessary thinking skills tools available, when learners enter adolescence which is known as the period of 'maximum growth and development with regard to mental functioning' (Singh, 2007:53), they will be able to fully utilize the thinking skills tools to its maximum worth for a higher level of evaluation and creativity.

By transmitting the practice of critical and creative thinking, it builds awareness in the children to be sensitive to environmental issues which will not disappear. On the contrary, the environmental problems which the world is currently facing may simply intensify as the human population increases, resulting in global implications (Hart and Nolan, 1999). Thus, Hutchison in 'Growing up Green' argues that the crucial period to nurture a child's mind is in the middle childhood, 'for the emergence of a child's 'working theory' of the world...to attend to children's ideas about nature and environment because certain values and beliefs may be rooted in this sensitive period of development' (1998 cited in Hart and Nolan, 1999:29).

Consequently, even as strategies are sought for educators and inquirers to work with, learners need to have 'a sense of oneself, including self as thinker and learner, and a sense of others and of interaction with them' (Fisher, 1999:52). This implies that inquirers need to develop the disposition and attitude to inquire and more importantly, virtues of 'affiliation to truth, honesty of expression and a respect for others' needs to be engrafted in the learner because 'it is by virtue of these that we are persons of one sort or another' (Fisher, 1999). Tilbury explains that, 'children must develop a sense of respect and caring for the natural environment during their first few years of life or be at risk of never developing these values' (1994a cited in Hart and Holan, 2006:30). 
All the same, in order for the cultivated skills to not be redundant, a positive environment even outside the classroom is essential to encourage continuous progress. Fisher warns that if all the skills acquired are not actually used, 'all the finely honed thinking skills in the world will be for naught' (Fisher, 1999:55). Thus, the development of a whole-school ethos as a learning community has been increasingly recognised (Boyd, 1997 cited in Fisher 1999).

This study is significant as it looks into the teaching and learning process of the implementation of the Six Thinking Hats theory in the ES classroom as well as the effects and thoughts about it. Due to the limitation and constraint in curriculum context, a long-term effect on learners' learning process was not seen in the research. Nevertheless, the enforcement of thinking skills is encouraged from a young age, as Hart and Holan have stated, 'although widely varied in 'findings' and 'results', a consistency of report connecting early life experience and life-long attitudes, values and patterns of behavior towards the environmental was found' (2006). Recommendation for further research includes studying a range of topics over the Environmental Education curriculum as well as getting the community and whole school involved over a longer period of time.

In conclusion, the Six Thinking Hats does encourage higher-order thinking skills in the teaching and learning process as it provides a support to not only the students but the teacher. While students' interests may vary according to circumstances and behaviour, the effectiveness of the Six Hats is seen to correspond to the awareness and maturity of individuals as well. As children are trained from a young age to develop their thinking skills and gain higher-order thinking skills, we may look forward towards a better tomorrow.

[1] R. Fisher, Thinking Skills, 2005.

\section{References}

[2] P. Hart, and K. Nollan, A Critical Analysis of Research in Environmental Education, Studies in Science Education, 34(1), 1999, 169.

[3] UNESCO, Environmental Education Activities for Primary Schools (Paris: UNESCO, 1992).

[4] F. J. King, L. Goodson, and F. Rohani, Higher Order Thinking Skills, 1998.

[5] E. De Bono, Six Thinking Hats (New York: Little Brown Company, 1999).

[6] National Environmental Education Foundation (NEEF), Benefits of Environmental Education 2010 (Washington: National Environmental Education Foundation, 2010).

[7] D. R. Krawthwohl, A Revision of Bloom's Taxonomy: An Overview, Theory into Practice, 41(4), 2002, $212-218$.

[8] R. Fisher, Thinking Skills to Thinking Schools: Ways to Develop Children's Thinking and Learning, Early Child Development and Care, 153 (1), 1999, 51-63.

[9] S. D. Schafersman, An Introduction to Critical Thinking, 1991.

[10] J. Marrapodi, Critical Thinking and creativity overview and comparison of the theories (ED7590 Critical Thinking and Adult Education, 2003)

[11] UNESCO, A Prototype Environmental Education Curriculum for the Middle School (Paris: UNESCO, 1994).

[12] D. D. Chiras, Environmental Science, $8^{\text {th }}$ Edition (Sudbury: Jones and Bartlett Publishers, 2010).

[13] C. Carmichael, Exploration of Critical Thinking in Environmental Subjects (Hons, University of Technology, 2006).

[14] D. Tarlinton, Bloom's Revised Taxonomy, 2003.

[15] F. F. McAleer, Pennsylvania Educational Leadership (a publication of the Pennsylvania Association for Supervision and Curriculum Development, PASCD, 2006).

[16] E. De Bono, Six Thinking Hats (Lancaster: The de Bono Group, 2011).

[17] D. Kruse, Thinking Tools for the Inquiry Classroom (Australia: Curriculum Corporation, 2010).

[18] S. House, M. R. A. Alonso, A. Paran, R. D. Martínez, and V. H. Hobbs, INGLÉS Investigación, innovación y buenas prácticas: Teacher Development, 2011.

[19] R. Ballantyne, J. Fien, and J. Packer, School Environmental Education Programme Impacts upon Student and Family Learning: A Case Study Analysis. Environment Education Research, 1(1), 2001, 23-37.

[20] C. A. Mertler, Action Research: Teachers as Researches in the Classroom (London: SAGE, 2006).

[21] N. Mack, C. Woodsong, K. M. MacQueen, G. Guest, and E. Namey, Qualitative Research Methods: A Data Collector's Field (US: Family Health International, 2005).

[22] B. G. Davis, Tools for Teaching, $2^{\text {nd }}$ Edition (CA: Jassey-Bass, 2009).

[23] Y. K. Singh, and B. Upadhya, Educational Psychology (India: APH Publishing Corporation, 2007). 